\title{
Intravenous buprenorphine/naloxone and concomitant oral pregabalin misuse: a case report
}

This article was published in the following Dove Press journal:

Neuropsychiatric Disease and Treatment

\author{
Burak Kulaksızoğlu ${ }^{1,2}$ \\ Hüseyin Kara ${ }^{1,2}$ \\ Berkan Bodur ${ }^{1,2}$ \\ Murat Kuloğlu' ${ }^{1,2}$ \\ 'Department of Psychiatry, Akdeniz \\ University School of Medicine, \\ Antalya, Turkey; ${ }^{2}$ Akdeniz University, \\ Alcohol and Substance Addiction \\ Treatment and Research Center, \\ Antalya, Turkey
}

\begin{abstract}
Opioid misuse and dependence are major medical and social concerns worldwide. Buprenorphine/naloxone combination (BNC) is a drug that has misuse potential and is used to treat opioid dependence, including buprenorphine and naloxone. Buprenorphine shows its pharmacological effects by binding to opioid receptors. Buprenorphine is a partial agonist and has smaller maximal effects compared to those of full agonists (heroin, methadone). Naloxone is a non-selective opiate antagonist added to buprenorphine for the prevention of intravenous diversion. BNC is used in the treatment of opioid dependence for detoxification and maintenance. The drug should be used as a sublingual film tablet. Pregabalin is used in the treatment of neuropathic pain, epilepsy and anxiety disorders. It is increasingly being reported as possessing a potential for misuse. In this article, we present a case of intravenous BNC and concomitant oral pregabalin misuse that developed in a monitored and treated patient for the reason of opioid dependence.
\end{abstract}

Keywords: intravenous buprenorphine-naloxone, pregabalin, drug misuse, opioid addiction

\section{Introduction}

Opioid misuse and dependence are important problems that cause extreme morbidity, mortality, disability and economic costs, leading to significant medical and social problems worldwide. ${ }^{1,2}$ Buprenorphine/naloxone combination (BNC) is a drug containing partial $\mu$-opioid receptor agonist buprenorphine and $\mu$-opioid receptor antagonist naloxone in 4/1 proportion for the treatment of opioid dependence. Buprenorphine's safety profile, ceiling effect at high doses, ability to be coformulated with naloxone to limit injection abuse and lower abuse potential compared to full opioid agonists make it a suitable medication for office-based treatment of opioid dependency. ${ }^{3}$ Naloxone is a non-selective opioid antagonist added to buprenorphine for the prevention of intravenous (iv) diversion. Naloxone is used to reverse the effects of opiate overdose, such as respiratory depression, sedation and hypotension, without a risk of developing tolerance, physical or psychological dependence. ${ }^{4}$

The effects of buprenorphine increase proportionally to the dose, until it reaches a plateau. This is called "ceiling effect", which makes buprenorphine safer than the full agonists at high doses. Hence, deaths from buprenorphine have been attributed to misuse (iv injection of crushed tablets) or concomitant use of sedatives and not to overdose. ${ }^{5}$ In a previous study, patients treated with BNC showed a significantly lower rate of positive results in urine for morphine and cocaine metabolites than those treated with naltrexone alone. ${ }^{6}$

The prescription of BNC is limited by the Turkish Ministry of Health, allowing treatments only in specialized centers. BNC has been officially approved since 
April 2010 in Turkey. Buprenorphine is a suitable drug for replacement therapy due to its partial opioid agonistic activity. ${ }^{7}$ Misuse potential for buprenorphine is generally considered to be less than other opioid agonists. ${ }^{8,9}$

Pregabalin is an anticonvulsant, specifically used in the management of neuropathic pain at $150-600 \mathrm{mg} / \mathrm{d}$, in adult patients. ${ }^{10}$ Pregabalin is widely used in neurology, psychiatry and primary health care services but is reported to have an increasing potential for misuse. ${ }^{11}$

In this case, the patient who started treatment due to opioid dependence 2 years ago and later on who misused iv BNC and concurrent oral pregabalin will be discussed. From this point of view, we think that it will contribute to the literature.

\section{Case}

The patient was 19 years old, male, single, secondary school graduate, hairdresser. In February 2018, he was admitted to our clinic, because of iv BNC and oral pregabalin misuse. He had been using heroin for 4 years. BNC treatment was started at a dose of $10 \mathrm{mg} / \mathrm{d}$ and was continued for 26 months. According to the information he gave, with the thought that the dose was not enough, he has started iv infusion of $10 \mathrm{mg}$ BNC daily from iv route over the last 6 months by dissolving it in drinking water under non-sterile conditions. During the 26-month treatment period, BNC was generally finished earlier than the prescription time, for this reason, he used pregabalin (at a dose of 600-2,400 mg/d), which he provided in several ways to get rid of the deprivation.

In interviews with the patient in our clinic, depressed mood, hopelessness and pessimism about not being able to recover from addiction were observed. In the patient's history, there were no medical illness, mental disorder and history of previous surgery. Complete blood count, liver and kidney function test results were normal. Hepatitis and HIV markers were negative. In urine toxicology, buprenorphine was positive, and other parameters were negative. After admission to the clinic, BNC dose was regulated to be $8 \mathrm{mg} / \mathrm{d}$ and quetiapine dose to be $200 \mathrm{mg} / \mathrm{d}$. During hospital stay, intense craving to pregabalin was observed, and heroin withdrawal symptoms were not observed. Carbamazepine $400 \mathrm{mg} / \mathrm{d}$, as well as buspirone $20 \mathrm{mg} / \mathrm{d}$, was added to the medical treatment for the control of craving to pregabalin, anxiety and impulsivity.

After 2 weeks of hospitalization, the patient decided that he did not want to continue to the treatment and decided to be discharged on his own request. So the treatment resulted in failure.

\section{Discussion}

The use of BNC in the treatment of opioid dependence is increasing day by day according to other treatment options. As a result, there are more cases of misuse of this drug.

Since buprenorphine was widely used for the treatment of opioid dependence in France in 1995, the illegal use and misuse of buprenorphine have been extensively documented. One study reported that $20 \%$ of the buprenorphine patients use iv drugs. ${ }^{12}$

Pregabalin misuse is also present in our case, as well as the use of iv BNC. According to our clinical observations, multiple drug misuse is a common condition, which reduces the success of the treatment. Our patient finished BNC earlier than prescribing time and did not comply with the treatment rules. He tried to overcome opiate deprivation by using up to 2,400 mg of pregabalin per day. He did not comply with the rules of treatment and eventually was discharged at his own discretion.

One study reported that $27 \%$ of the iv drug users used buprenorphine by injection and $37 \%$ had multiple drug use. ${ }^{13}$ In our case as well, iv BNC and concomitant pregabalin misuse has been seen. Another study for comparing abuse liability of iv buprenorphine vs buprenorphine/naloxone showed that formulations with larger absolute naloxone may be less abusable because of precipitating a greater degree of withdrawal. ${ }^{14}$

Filipetto et $\mathrm{al}^{15}$ reported that a 35 -year old female patient who started to use pregabalin for pain relief was later on referred to a detoxification center, as a result of the development of withdrawal symptoms, due to the use of pregabalin at a dose of $600 \mathrm{mg} / \mathrm{d}$ - the maximum recommended daily dose. In another case report, Grosshans et $\mathrm{al}^{16}$ reported about a 47-year old male patient with pregabalin dependence and concurrent cannabis and alcohol use.

Another approach to reducing street demand for illegal buprenorphine may be to increase the availability of BNC. Market economy guidelines suggest that costs can be reduced with greater usability, and the use of care services may increase. This can potentially reduce the demand for illegal buprenorphine. ${ }^{3}$

$\mathrm{BNC}$ is a drug with potency for misuse. In contrast, $\mathrm{BNC}$ has proven clinical effectiveness in the treatment of opioid dependence and is used extensively in treatment as the first choice in many countries. In addition, patients taking BNC treatment may have the wrong drug use (for example, inappropriate dosing, inhalation or injection) as an indication of insufficient dosing or dissatisfaction. These incompatibility conditions in treatment may be indication 
or alert for doctors to adjust the dose in opioid substitution therapy.

Excessive control over the use of BNC may reduce the desire for the treatment of dependent individuals, and "black market" sales may become more open and dangerous. For this reason, parallel to the increase in control mechanisms, it may also be necessary to increase the access to treatment for dependent individuals. For dependent individuals, increasing access to treatment options should be considered in parallel to the increase in follow-ups and controls.

Two important features of this case are as follows: this is the first case of iv use of BNC reported in Turkey and also the first in the literature for the concomitant iv BNC and oral pregabalin misuse.

There is a need for more research to understand BNC misuse and unmedicated use and motivating factors, especially in a context consistent with the therapeutic purpose of the drug. Future clinical trials may examine the feasibility and efficacy of buprenorphine, which is routinely prescribed for people who want to avoid illegal opioid use. Studies to be done to understand the efficacy of new forms of buprenorphine, including subdermal and transdermal patches, intramuscular depot forms and implants, will shed light on the future of opioid dependence treatment strategies.

\section{Disclosure}

The authors report no conflicts of interest in this work.

\section{References}

1. Degenhardt L, Hall W, Warner-Smith M. Using cohort studies to estimate mortality among injecting drug users that is not attributable to AIDS. Sex Transm Infect. 2006;82(Suppl 3):iii56-iii63.

2. Strassels SA. Economic burden of prescription opioid misuse and abuse. J Manag Care Pharm. 2009;15(7):556-562.
3. Yokell MA, Zaller ND, Green TC, Rich JD. Buprenorphine and buprenorphine/naloxone diversion, misuse, and illicit use: an international review. Curr Drug Abuse Rev. 2011;4(1):28-41.

4. Tzatzarakis MN, Vakonaki E, Kovatsi L, et al. Determination of buprenorphine, norbuprenorphine and naloxone in fingernail clippings and urine of patients under opioid substitution therapy. J Anal Toxicol. 2015;39(4):313-320.

5. Belivanis $\mathrm{S}$, Tzatzarakis MN, Vakonaki E, et al. Buprenorphine and norbuprenorphine levels in head hair samples from former heroin users under Suboxone ${ }^{\circledR}$ treatment. Drug Test Anal. 2014;6(Suppl 1):93-100.

6. Gerra G, Fantoma A, Zaimovic A. Naltrexone and buprenorphine combination in the treatment of opioid dependence. J Psychopharmacol. 2006;20(6):806-814.

7. United States National Institutes of Health. National Institute on Drug Abuse (NIH/NIDA). Buprenorphine: an alternative treatment for opioid dependence. In: Blaine J, editor. NIDA Research Monograph Series; 1992. Available from: https://archives.drugabuse.gov/sites/default/files/ monograph121.pdf. Accessed November 05, 2018.

8. Sigmon SC, Moody DE, Nuwayser ES, Bigelow GE. An injection depot formulation of buprenorphine: extended bio-delivery and effects. Addiction. 2006;101(3):420-432.

9. Baumevieille M, Haramburu F, Bégaud B. Abuse of prescription medicines in southwestern France. Ann Pharmacother. 1997;31(7-8): $847-850$.

10. Toth C. Drug safety evaluation of pregabalin. Expert Opin Drug Saf. 2012;11(3):487-502.

11. Schifano F. Misuse and abuse of pregabalin and gabapentin: cause for concern? CNS Drugs. 2014;28(6):491-496.

12. Auriacombe M, Fatséas M, Dubernet J, Daulouède JP, Tignol J. French field experience with buprenorphine. Am J Addict. 2004;13(Suppl 1): S17-S28.

13. Moatti JP, Vlahov D, Feroni I, Perrin V, Obadia Y, Odabia Y. Multiple access to sterile syringes for injection drug users: vending machines, needle exchange programs and legal pharmacy sales in Marseille, France. Eur Addict Res. 2001;7(1):40-45.

14. Jones JD, Manubay JM, Mogali S, et al. Abuse liability of intravenous buprenorphine vs. buprenorphine/naloxone: Importance of absolute naloxone amount. Drug Alcohol Depend. 2017;179:362-369.

15. Filipetto FA, Zipp CP, Coren JS. Potential for pregabalin abuse or diversion after past drug-seeking behavior. J Am Osteopath Assoc. 2010; 110(10):605-607.

16. Grosshans M, Mutschler J, Hermann D, et al. Pregabalin abuse, dependence, and withdrawal: a case report. Am J Psychiatry. 2010; 167(7):869.
Neuropsychiatric Disease and Treatment

\section{Publish your work in this journal}

Neuropsychiatric Disease and Treatment is an international, peerreviewed journal of clinical therapeutics and pharmacology focusing on concise rapid reporting of clinical or pre-clinical studies on a range of neuropsychiatric and neurological disorders. This journal is indexed on PubMed Central, the 'PsycINFO' database and CAS,

\section{Dovepress}

and is the official journal of The International Neuropsychiatric Association (INA). The manuscript management system is completely online and includes a very quick and fair peer-review system, which is all easy to use. Visit http://www.dovepress.com/testimonials.php to read real quotes from published authors. 